\title{
Behavioural risk factors of non-communicable diseases among adolescents
}

\author{
Adhikari K, Adak M R \\ Department of community medicine and Department of Biochemistry, National Medical College and teaching hospital, \\ Birgunj, Nepal \\ Correspondence to: K. Adhikari, Department of community medicine, National Medical College and teaching hospital, \\ Birgunj, Nepal. \\ E-mail: kishoo2005@yahoo.com
}

\begin{abstract}
Introduction: Cardiovascular and other chronic diseases are becoming the major causes of morbidity and mortality in most of the third world countries, including Nepal. Unhealthy diet, physical inactivity and consumption of tobacco, alcohol, drugs etc. are major global determinants of non-communicable diseases and contribute to the excess death and disability among the poor in terms of mortality. This study was done to estimate the prevalence of behavioral risk factors of NCDs among adolescent.
\end{abstract}

Methods: A cross sectional study based on WHO stepwise approach for surveillance of NonCommunicable Diseases (NCDs) risk factors was conducted in Chitwan District to assess the risk factors of NCDs. Information was collected on substance abuse, dietary habits and physical activity through personal interview.

Results: About $50 \%$ male and $30 \%$ female respondents were currently abusing one or other forms of substance. Male (39\%) and female (26\%) were using tobacco products. It was found that only $14 \%$ of respondents were doing satisfactory level of physical activities.

Conclusions: Substantially high levels of the various behavioral risk factors among adolescents in Chitwan District suggest an urgent need for awareness raising programmes.

Key words: Addiction, Non-communicable Diseases (NCDs), Risk factors.

\section{Introduction}

As correct dose of medicine is essential for treating an illness, similarly there is an equally important role of healthy diet and physical exercise for promotion of good health. Scientific evidence shows that unhealthy diet, physical inactivity and substance use like tobacco, alcohol, drugs etc. are major global determinants of non-communicable diseases (NCDs). ${ }^{1}$ The World Health Organisation (WHO) has documented that developing countries are suffering from double burden of diseases. About $90 \%$ of the world's total disease burden occurs in developing countries, while only $10 \%$ of health expenditures are allocated there. ${ }^{2}$ Currently the NCDs affects more poor people and these also contribute to the excess death and disability among the poor in term of mortality. ${ }^{3}$
The NCDs are cardiovascular, renal, nervous, mental diseases, arthritis, chronic non-specific respiratory diseases, permanent results of accidents, senility, blindness, and chronic results of communicable diseases. ${ }^{4}$ Most of these NCDs share preventable risk factors such as tobacco use, high alcohol consumption, hypertension, sedentary life style and obesity. ${ }^{5}$ Out of all NCDs, cardio-vascular diseases (CVDs) are most significant diseases in respect to mortality and morbidity. ${ }^{6-9}$ Most of the behavioural risk factors are potentially modifiable ones. ${ }^{10}$

Among the all risk factors of NCDs, tobacco use remains as an important risk factors. It was estimated that about 5 million premature deaths in the world was attributed to smoking and 4 million of these deaths were in men. ${ }^{11}$ It has been reported that regular smoking can increase the risk 
not only of NCDs, but also of many other health hazards. ${ }^{12}$ High consumption of alcohol and exposure of cigarette smoking may directly causes cirrhosis of the liver, cancer of the mouth, pharynx, pancreas and oesophageal cancer. ${ }^{13}$

Unhealthy diets and physical inactivity are two of the main risk factors for raised blood pressure, raised blood glucose, abnormal blood lipids, overweight/obesity, and for the major NCDs such as cardiovascular diseases, cancer, and diabetes. ${ }^{14}$ High calorie diet and less physical exercise play a vital role for increasing the prevalence of obesity. Overall, 1.9 million deaths are attributable to physical inactivity. Physical inactivity has been identified as a leading risk factor in recent "world health reports" of the World Health Organization.1 In the developing countries, obesity is positively correlated with higher socioeconomic status, while in the developed countries blood pressure with obesity is negatively associated with socioeconomic status. $^{15}$

As NCDs are increasing rapidly in the developing world, the efforts for measuring and controlling the trend of NCDs is found inadequate. To anticipate the epidemic in NCDs, World Health Organization (WHO) has initiated the worldwide surveillance of risk factors using the WHO STEP-wise approach to Surveillance of risk factors for non-communicable diseases. ${ }^{16}$ WHO reported that $60 \%$ of all deaths in the world are now caused by NCDs and every third death in the world is caused by cardiovascular diseases. ${ }^{17}$

NCDs are known to be increasing at an alarming pace in South-east Asian region (SEAR) where rapid changes in the economic, social and demographic determinants of health as well as embracing of unhealthy lifestyle in large segment of population are the contributing factors for NCDs. ${ }^{18}$

In Nepal, NCD associated morbidity and mortality is not documented in standardized format. It was estimated that the prevalence of CVD is $5.6 \%$ in the mountain area, $1.5 \%$ in the hills, and $5 \%$ in the Terai. It has also been reported that the prevalence of hypertension among adults is $5-20 \%$ and diabetes mellitus is $15 \%$ in urban and $2 \%$ in rural areas in the age group 15 years. ${ }^{19}$ However, due to lack of systematic reporting, many cases of morbidity and mortality might have been omitted in the reported figures. The department of health services (FY 2006-2007) registered $81.73 \%$ of all hospital visits as cases of NCDs at national and regional health institutions. ${ }^{20}$

\section{Methods}

This is a cross-sectional study conducted on both urban and rural areas of Chitwan District and lasted for six months from 15th May to 25th Nov 2009. The Study is based on WHO stepwise approach for surveillance of NCDs risk factors. ${ }^{16}$ The sample size was 1650 comprising both sexes aged $15-19$ years by using the formula $n=4 \mathrm{pq} / \mathrm{d} 2$ (where $\mathrm{d}$ is the allowed error taken as $0.05, \mathrm{p}=\mathrm{q}=0.5$ ).21 A multistage cluster sampling design was adopted for the study. 712 respondents from the urban areas and 938 from rural setting were selected in the study among them 925 were male and 725 were female. Prior to the interview, consent was obtained from the respondents. The investigators met each of them and collected information on substance abuse, dietary patterns and physical activities by using a pretested set of questionnaire.

Classification of physical exercise was done by following the Global Physical Activity Questionnaire (GPAQ) which was developed by WHO for physical activity surveillance in countries. ${ }^{22}$

\section{Results}

The total number of respondents for the study was 1650 adolescents, 925 boys and 725 girls. The response rate was 95 per cent, excluding the non $\neg$ residents who were away from their native place. A total of 712 respondents were from urban and 938 respondents were taken from rural areas.

The male respondents was found higher user of any forms of substances than female. Out of total respondents; about $50 \%$ male and $30 \%$ female were found using one or other forms of substances (Fig.1).

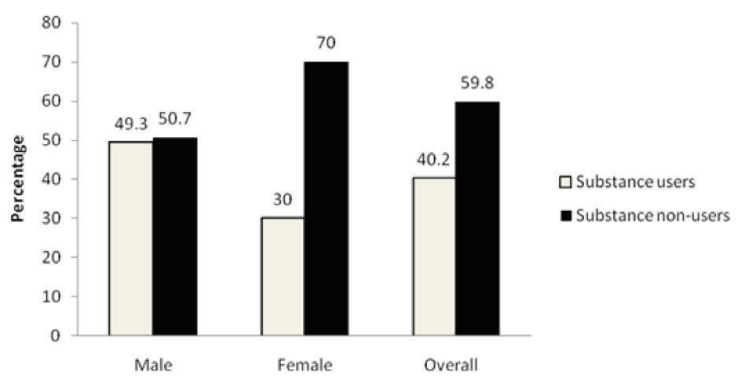

Fig. 1: Sex wise distribution of substance use

Nearly $40 \%$ of male respondents and 23 per cent of female respondents were using tobacco in one or other forms. The percentages of male and female alcohol user were 26.8 and 18.2 respectively. About $15 \%$ of male respondents were using one or other forms of narcotics whereas $8 \%$ female respondents were also found using some forms of narcotics. Higher percentage of respondents were found using opium in both sexes (male $9.3 \%$ and female $5.4 \%$ ) followed by 
nitrazepam (male $4.5 \%$ and female $3.6 \%$ ) (Table 1).

It has been reviled that majority of adolescents were influenced by their friends $(78.8 \%)$, Co-workers $(10.0 \%)$ and siblings (7.5\%) for substance use (Fig. 2).

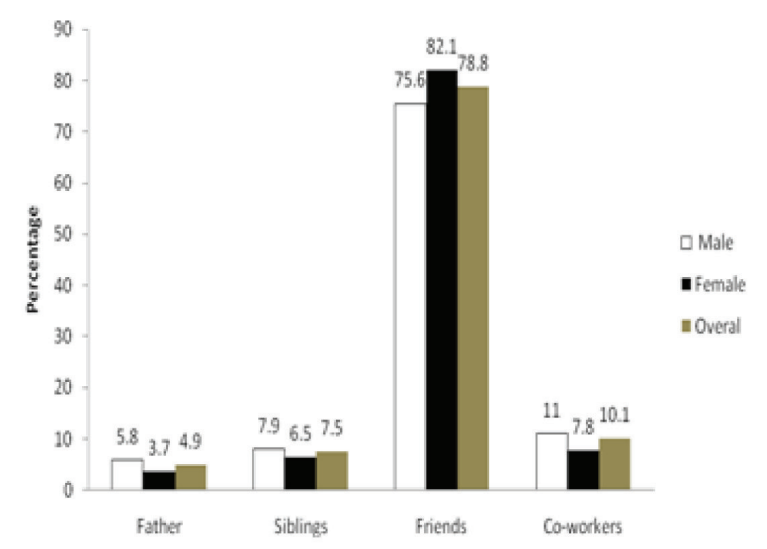

Fig. 2: Person influencing for substance abuse

It has been found that high percentages of respondents (26.2\%) were consuming large amount of salt per day. Comparatively more number of female respondents (32.9\%) was found consuming high amount of salt per day than male $(20.9 \%)$ (Table 2).

Very high proportions of respondents were found consuming more than 30 percentage calories from the dietary fats $(37.6 \%)$. Fat consumption was found very high among the male respondents $(36.8 \%)$ than the female (38.4\%) (Fig.3).

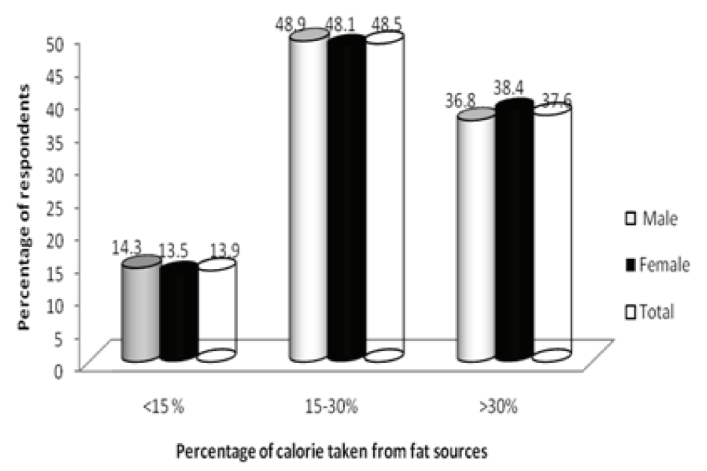

Fig. 3: Respondents taking percentage of calorie from dietary fat

It has been found that very high proportion of respondents $(56.5 \%)$ male and $67.9 \%$ female) were found doing inadequate level of physical activity whereas only $20 \%$ male and about 5\% female were found spending highly physically active life (Table 3 ).

\section{Discussion}

As the aim of the study was to assess the prevalence of behavior risk factors among adolescents which are responsible for several non-communicable diseases, we collected information regarding NCDs risk factors under 3 headings i.e. substance abuse, dietary patterns and physical activity.

It was found that about $50 \%$ of male and $30 \%$ of female respondents were using substances. Nearly $40 \%$ of male respondents and 23 per cent of female respondents were using tobacco in one or other forms. Similar study conducted on school children of grade 8,9 and 10 in central region of Nepal has reported over all $16.3 \%$ of respondents ever used tobacco product in any form and the rate among boys was significantly higher than that among girls. 23 The increased prevalence of tobacco use in the present study might be due to higher aged respondents. Another study reported the overall smoking prevalence in Nepal for the population aged fifteen or more is $37.4 \%$ and there also higher percentage of males $(47 \%)$ were tobacco user compared to female counterpart $(27.6 \%){ }^{24}$

It was found that overall $26.8 \%$ male and $18.2 \%$ female respondents were taking one or other type of alcohol. Among the alcoholic substances, beer was the highly used substances (male $25.4 \%$ and female $16.1 \%$ ) followed by wine (male $7.1 \%$ and female $2.9 \%$ ) and jand (male $2.6 \%$ and female $1.5 \%$ ). A similar study conducted in Nepal reported that $48.3 \%$ male and $27.7 \%$ female ere currently using some type of alcohol. This high prevalence comparing to present study may be due to taking respondents wider age range in the study. ${ }^{25}$

About $15 \%$ of male respondents were using one or other forms of narcotics whereas $8 \%$ female respondents were also found using some forms of narcotics. Among the narcotics, opium was the highly used narcotics by both sexes (male $9.3 \%$ and female $5.4 \%$ ). Nitrezapam, opium and cannabis were other mostly used drugs among the respondents. Surprisingly, some percentages of respondents were found using glue and boot-polish as addiction. A similar study conducted in Nepal in 2001 reported that cannabis (72.2\%) Heroin $(2.2 \%)$, opium $(6.7 \%)$ and others like glue, boot polish, iodex (7.8\%).25

Fats are very rich sources of energy. Everybody in the world is having fats in his or her lives. However, consumption of fat is risk for different forms of cancers and heart diseases. It was found from the present study that majority of the respondents were consuming fats more than the WHO recommended level. About $37 \%$ male and $14 \%$ of female respondents were found getting more than $30 \%$ of calorie 
from fat sources. The dietary goals recommended by the various expert committees of WHO has suggested that dietary fat should be limited to approximately $15-30$ per cent of total daily calorie intake. ${ }^{26-27}$

It has been found that high percentages of respondents (26.24\%) were consuming large amount of salt (more than 15 gram) per day. Comparatively more number of female respondents $(32.96 \%)$ was found consuming high amount of salt per day than male $(20.97 \%)$. only $42 \%$ of respondents were found using normal level of salt per day. WHO recommendation is less than 5-10 grams salt per day. If it increases more than this, there will be risk for developing cancers and different forms of health diseases. ${ }^{28}$

The role of physical activity in the prevention of overweight and obesity is a very important one, and the WHO Global Strategy on Diet, Physical Activity and Health (WHO 2004) states: "Diet and physical activity influence health both together and separately. Although the effects of diet and physical activity on health often interact, particularly in relation to obesity, there are additional health benefits to be gained from physical activity that are independent of nutrition and diet, and there are significant nutritional risks that are unrelated to obesity. Physical activity is a fundamental means of improving the physical and mental health of individuals." 29 It has found that about $62 \%$ of respondent $(56.54 \%$ male and $67.86 \%$ female) were found doing inadequate level of physical activity. Only $20 \%$ male and about $5 \%$ female respondents were found doing sufficiently active physical activity. 'Comparative quantification of health risk' published by WHO, 2004 has defined three level of exposure i.e. "level 1 or inactive" as doing no or very little physical activity at work, at home, for transport or during discretionary time. "level 2 or insufficiently active" as doing some physical activity but less than 150 minutes of moderate-intensity physical activity or 60 minutes of vigorous-intensity physical activity a week. And "level 3 or sufficiently active" is defined as at least 150 minutes of moderate-intensity physical activity or 60 minutes of vigorous-intensity physical activity per week. ${ }^{30}$

\section{Conclusion}

Very high proportions of adolescents of Chitwan district are having various behavioural risk factors. This high prevalence of risk factors necessitates an urgent need for awareness raising programmes for developing healthy life styles like regular physical activities and habit of healthy diet. Strong legal enforcement is needed for discouraging substance abuse of various forms.

\section{References}

1. World Health Organization. The world health report 2002. Reducing risks, promoting healthy life Geneva: WHO, 2002.

2. Murray CJL, Lopez AD. The Global Burden of Disease: a comprehensive assessment of mortality and disability from diseases, injures and risk factors in 1990 and projected to 2020. Cambridge (MA): Harvard University Press; 1996.

3. Gwatkin DR, Gulliot M, Heuveline P. The burden of disease among the global poor: Current situation. Future trends and implication for strategy. Washington, DC, the international bank for reconstruction and development, the World Bank 2000; 1-44.

4. Park K. In: Park's Text Book of preventive and social medicine; 19th ed. Jabalpur, Banaroidas Bhanot Publisher 2005; 285.

5. Schuit AJ, von Loon AJ, Tijhuis M, Ocke M. Clustering of life time risk factors in general adult population. Prev Med 2002; 35: 219-24.

6. Yusuf HR, Gilis WH, Croft JB, Anda RF, Casper ML.Impact of multiple risk factor profiles on determining cardiovascular disease risk. Perv Med 1998; 27: 1-9.

7. Chang M, Hahn AR, Teutsch Hutwagner LC. Multiple risk factors and population attributable risk for ischemic heart disease mortality in the United State, 1971-1992. J Clin Epidemiol 2001; 54: 634-44.

8. Gaffar A, Reddy KS. Burden of non-communicable diseases in South Asia. Brit Med J 2004; 328: $607-$ 810 .

9. Salin Y, Srinath R, Stephanie O, Sonia A. Global Burden of Cardiovascular disease. Circulation 2001; 104: 2746-53.

10. Coleman CA, Friedman AG, Burright RG. The relationship of daily stress and health related behaviors to adolescents cholesterol level. Adolescence 1998; 33: 447- 60.

11. Ezzati M, Lopze A. Estimates of global mortality attributable to smoking in 2000. Lancet 2003; 362: 847-52.

12. Iribarren C, Takawa IS, Sidney S, Friedman GD. Effect of cigarette smoking on the risk of cardiovascular disease, chronic obstructive pulmonary disease and cancer in men. $\mathrm{N}$ Eng $\mathrm{J}$ Med 
1999; 340: 1773-80.

13. Castellsague X, Munoz N, de Stefani E, Victoria CG, Casteletto R, Rolon PA, et al. Independent and joint effects of tobacco smoking and alcohol drinking on the risk of oesophageal cancer in men and women. Int J Cancer 1999; 82: 657-64.

14. Valcone T. Health related behaviors and their mortality consequences, an overview. International population conference. Montreal, Vol-1, International Union for the study of population (IUSP), Liege Balgium,1993; 443-7.

15. Colhoun HM, Hemingway H, Poulter NR. Socioeconomic status and blood pressure, an overview analysis. J Hum Hyperten 1998; 12: 91-110.

16. World Health Organization (WHO). Step wise approach to surveillance (STEPS). http//www. Who.int/chp/steps/en/ (accessed 2006 May 1).

17. Ko GT, Chan JC, Woo J, Lau E, Yeung VT, Chow $\mathrm{CC}$ et al. Simple anthropometric indexes and cardiovascular risk factors in Chinese. Int J Obes Relat Metab Disord 1997; 21: 995-1001.

18. Barry P, Sue H, Soowon K. The nutrition transition and prevention of diet-related diseases in Asia and the Pacific. Food Nutri Bull 2001; vol. 22, no. 4 (Supplement): 1-58.

19. WHO. Surveillance of Major Non-communicable diseases in the South-East Asia Region 200; p.9-10.

20. Annual report (2006/2007). Department of health services, Nepal.

21. Wayne. WD. Bio Statistics, A foundation for analysis in the health sciences. New York: John Wiley \& Sons Inc 1995; p. 180-1.

22. The Global Physical Activity Questionnaire (GPAQ) analysis guide. Surveillance and population-based prevention department of chronic diseases and health promotion World Health Organization 20 Avenue Appia, 1211 Geneva 27, Switzerland.

23. Pandey MR, Pathak BP. Global youth tobacco survey in central development region of Nepal. Challenges of Tobacco Use Behavior, 2002.

24. Karki YB, Panta KD, Pande BR. A study on the economics of tobacco in Nepal. Health Nutrition and Population Discussion Paper. Oct. 2003.

25. Dhital R, Subedi G, Gurung YB, Hamal P.
Alcohol and drugs use in Nepal. Child workers in Nepal concerned center (CWIN), May 2001.

26. WHO Technical Representative Services, 1982, 678.

27. WHO Technical Representatives Services, 1986, 732.

28. Usitalo U, Pietinen P, Puska P. Diet, nutrition and the prevention of chronic diseases. Geneva: Joint WHO/ FAO Expert Consultation report 2003.

29. WHO Global strategy on diet, physical activity and health. Geneva 2004. http://www.who.int/ dietphysicalactivity/en Cited 5 Jan 2006.

30. Wannamethee SG, Shaper AG, Albeti. Physical activity, metabolic factors and incidence of coronary heart disease and type 2 diabetes. Arch Int Med 2000; 160: $2108-16$ 